\title{
A Targeted Review of Computer-Assisted Learning for People with Autism Spectrum Disorder: Towards a Consistent Methodology
}

\author{
Sue Fletcher-Watson
}

Received: 14 June 2013 /Accepted: 9 August 2013 / Published online: 14 November 2013

(C) Springer Science+Business Media New York 2013

\begin{abstract}
Computer-assisted learning is an approach which has been used widely to support people with autism spectrum disorders. Commercial and research-driven technologies continue to be produced at a rapid rate, particularly mobile device applications. However, the field lacks a consistent, evidencebased methodology for design, implementation and evaluation of these technologies. This review collates published evidence for the value of CAL in autism education and therapy, with a specific view to identifying best practice in design, implementation and evaluation. The future of research in CAL for autism is considered including the need for relevant theoretical underpinnings, and appropriate responses from researchers and practitioners to novel technologies.
\end{abstract}

Keywords Autism spectrum disorders ·

Technology-enhanced learning $\cdot$ Technology $\cdot$ Computers ·

Education · Therapy · Intervention · Methodology

\section{Introduction}

Autism spectrum disorder (ASD) refers to a spectrum of developmental conditions, united by behavioural atypicalities in three areas: social communication, interaction and flexibility/imagination (Wing and Gould 1979). Computerassisted learning (CAL) approaches have been widely used to help support the learning of children and young adults with ASD (Goldsmith and LeBlanc 2004; Pennington 2010; Panyan 1984; Strickland 1997). A recent rush of systematic reviews indicate that CAL can be effective in teaching a variety of topics (Grynszpan et al. 2013; Ramdoss et al. 2011a, b; Kagohara et al. 2013) including social skills (Ramdoss et al. 2012). There are also recent findings to verify the common assumption that people with ASD spend a lot of time using computers (Mineo et al. 2009; Orsmond and Kuo 2011; Shane and Albert 2008).

Since the turn of the millennium, there has been a sharp increase in published academic output in the field. In the 1990s, nine experimental papers were published on this topic, but in the years 2000-2009 there were 30 journal articles reporting new data and there have already been ten studies reporting new data published since 2010 . In the commercial sector, there is parallel evidence of a recent explosion in technologies for people with ASD, for example in an online list of over 345 mobile device applications, or 'apps' marketed for people with ASD or their families. ${ }^{1}$

Given the proliferation of autism-specific software, the rapid rate of creation of novel technologies and the frequently positive evidence for their efficacy, it is crucial to define best practice for research in this field (Rajendran 2013; Moore et al. 2000). CAL projects for people with ASD often represent excellence in collaborative, interdisciplinary research where computer programmers work with psychologists, teachers, parents and others to create bespoke technology, but this element is rarely shared in published findings. There are papers which suggest best practice in the design of technologies for people with ASD (e.g. Cobb et al. 2002; Frauenberger et al. 2013; Frauenberger et al. 2011; Porayska-Pomsta et al. 2011) but these reports in computing and design journals may not have been read by researchers with a primary interest in autism, from disciplines such as medicine, psychology or education.
S. Fletcher-Watson $(\bowtie)$

Moray House School of Education, University of Edinburgh, 2.02 St

John's Land, Holyrood Road, Edinburgh EH8 8AQ, UK

e-mail: sue.fletcher-watson@ed.ac.uk

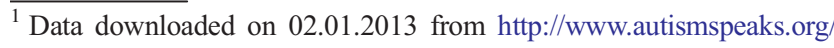
autism-apps
} 
There exist studies using gold-standard methodologies such as randomised controlled trials to evaluate CAL approaches (Bolte, et al. 2002; Beaumont and Sofronoff 2008; Faja et al. 2011; Tanaka, et al. 2010) but it is questionable whether this methodology is appropriate for such a fast-changing field. Additionally, it is unclear what should be the appropriate outcome measures for CAL intervention studies, especially when it often proves challenging to demonstrate that skills learnt in a CAL setting can generalise to real-world interactions or even novel stimuli (e.g. Golan and Baron-Cohen 2006).

This review paper brings together published data-driven research on CAL and autism to identify common features of successful interventions and make a step towards a consistent model for research on technologies for autism. Instead of reviewing papers based on their methodology or results, information is extracted on how technologies were designed, implemented and evaluated in an effort to define best practice for this field.

Throughout this review, the abbreviation CAL, for computer-assisted learning, is used to refer to the technique of using computers, computerised devices such as iPads and targeted software, to provide education and therapy for people with ASD. The focus on 'learning' is somewhat misleading. Though CAL can promote academic learning (Pennington 2010), computers are increasingly being employed as a medium for imparting knowledge about social skills (e.g. Rajendran and Mitchell 2000), and life skills (e.g. Self et al. 2007), and this might more properly be referred to as 'computer-assisted therapy'. Nevertheless, for simplicity, the term CAL is used throughout this review to refer to both educational and therapeutic computerised approaches.

This review has two important exclusions. First, robotics studies are not included. There is an increasing amount of work in what can be called 'developmental robotics' both using models of typical development to inform robot design and learning, and designing robots for use as therapeutic aids for atypical development (Barakova et al. 2009; Dautenhahn et al. 2009; Farr 2010; Giannopulu 2010; Ijichi and Ijichi 2007; Wuang et al. 2010). Though these are obviously technological solutions, they will not be covered here, because the work does not involve the individual interacting with a computer program in the traditional sense, because the field is still in its infancy and because the technical knowledge required to evaluate significant aspects of the work are outside the author's expertise.

A second exclusion is studies in which a child interacts with something more like a gadget than computer software. This exclusion incorporates video-modelling (Rayner et al. 2009; Delano 2007), studies in which teaching is supported by the use of (for example) PowerPoint slides (e.g. Coleman-Martin et al. 2005) and studies exploring the use of devices such as communication aids (e.g. Blishak and Schlosser 2003). The key issue uniting these exclusions, is that CAL, for the purposes of this review, should allow meaningful independent interaction by the student with a technological interface.

\section{Method}

Papers for inclusion in this review were sourced in four ways:

1. A search was conducted in PubMed on 21.11.2011 and again on 28.03.2013 using search terms covering variations on "autism" and "computer"2 These searches yielded a combined total of 696 results which were downloaded. A check of titles and abstracts reduced this to a list of 86 publications selected as relevant for closer attention and consideration for inclusion in the review.

2. Key papers from the list above were identified and handsearches conducted of their reference sections, to find older, related papers

3. Key papers were entered into the "Google Scholar" website and a 'cited by' search conducted to find more recent, related papers

4. Key authors were identified, contacted and asked to send details of publications on the topic, including any recently completed or unpublished work

A final list of 52 reports of novel data on the use of CAL for the education or therapeutic support of people with ASD found via these methods is included in this review and detailed in Table 1. From each paper, information was extracted about the way in which the technology was designed, the implementation method (e.g. the environment in which it was applied) and the evaluation system used. In many cases specific details in one or more of these categories was not available in the published data. This is thought to reflect not a lack of attention to these processes by the authors, but an absence of an appropriate space to report these features in traditional experimental reports.

\section{Results}

Papers are discussed under three topic headings, reflecting areas of current methodological uncertainty: design, implementation and evaluation. Relevant details are extracted and links made, where possible, to outcome.

\section{CAL in Autism: Lessons for Design}

The majority of studies investigated for this review report on the use of programs created specifically for the research

\footnotetext{
${ }^{2}$ Search terms: (("computers"[MeSH Terms] OR "computers"[All Fields] OR "computer"[All Fields]) AND ("autistic disorder"[MeSH Terms] OR ("autistic"[All Fields] AND "disorder"[All Fields]) OR "autistic disorder"[All Fields] OR "autism"[All Fields])) AND ("2008/03/ 30"[PDat]: "2013/03/28"[PDat])
} 
Table 1 Reports of novel data on the use of CAL for the education or therapeutic support of people with ASD

\begin{tabular}{|c|c|c|c|c|c|c|c|c|c|c|c|c|c|c|c|c|c|c|c|c|c|c|c|c|}
\hline & \multicolumn{3}{|c|}{ Design } & \multicolumn{3}{|c|}{ Methods } & \multicolumn{6}{|c|}{ Implementation } & \multicolumn{10}{|c|}{ Evaluation } & \multicolumn{2}{|c|}{ | Findings } \\
\hline & $\begin{array}{l}\text { 호 } \\
0 \\
0 \\
0 \\
1 \\
0\end{array}$ & 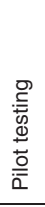 & 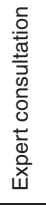 & z & 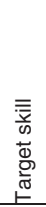 & 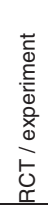 & 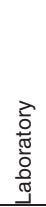 & $\begin{array}{l}\stackrel{0}{E} \\
\text { 오 }\end{array}$ & $\begin{array}{l}\overline{0} \\
\frac{7}{0} \\
\text { is }\end{array}$ & 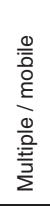 & 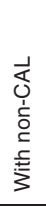 & 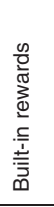 & 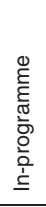 & $\begin{array}{l}\bar{d} \\
\mathbb{0} \\
\frac{0}{0} \\
\frac{0}{0} \\
\frac{\pi}{0} \\
\frac{\pi}{0} \\
\omega\end{array}$ & $\begin{array}{l}\text { 을 } \\
\stackrel{0}{\mathbb{N}} \\
\geq \\
0 \\
0 \\
0 \\
0\end{array}$ & 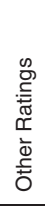 & 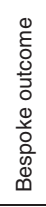 & 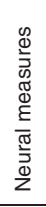 & 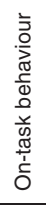 & 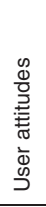 & 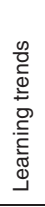 & $\begin{array}{l}\text { 윽 } \\
\sum_{3}^{1} \\
\text { o } \\
\text { 인 }\end{array}$ & $\begin{array}{l}0 \\
\stackrel{D}{0} \\
0 \\
0 \\
0\end{array}$ & $\begin{array}{l}\text { D } \\
\stackrel{\times}{\Sigma}\end{array}$ \\
\hline $\begin{array}{l}\text { Basil \& Reyes } \\
2003\end{array}$ & & & & 2 & $\mathrm{~L}$ & & & & $\checkmark$ & & $\boldsymbol{v}$ & & $v$ & $\boldsymbol{v}$ & & & & & & & & $\checkmark$ & $\checkmark$ & \\
\hline $\begin{array}{l}\text { Beaumont \& } \\
\text { Sofronoff, } 2008\end{array}$ & & $\checkmark$ & & 49 & $\mathrm{~S}$ & $\checkmark$ & & & & $\checkmark$ & $\checkmark$ & $\checkmark$ & & $\checkmark$ & & $\checkmark$ & & & & & & $\checkmark$ & $\boldsymbol{v}$ & \\
\hline $\begin{array}{l}\text { Bernard-Opitz et } \\
\text { al. } 1999\end{array}$ & & & & 10 & C & $\checkmark$ & $\checkmark$ & & & & $\checkmark$ & $\checkmark$ & & & $\checkmark$ & $\checkmark$ & & & & $\checkmark$ & $\checkmark$ & & $\checkmark$ & \\
\hline $\begin{array}{l}\text { Bernard-Opitz et } \\
\text { al. } 2001\end{array}$ & & & & 16 & $\mathrm{~S}$ & $\checkmark$ & $\checkmark$ & & & & $\checkmark$ & $\checkmark$ & $\checkmark$ & & $\checkmark$ & & $\checkmark$ & & & & & & & $\checkmark$ \\
\hline Bishop 2003 & & & & 10 & $\mathrm{~S}$ & & $\checkmark$ & & & & & & & & & & & & & $\checkmark$ & & & $\checkmark$ & \\
\hline Bolte et al. 2002 & & 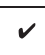 & & 10 & $\mathrm{E}$ & $\checkmark$ & $\checkmark$ & & & & & $\checkmark$ & $\checkmark$ & $\checkmark$ & & $\checkmark$ & & & & & & & & $\checkmark$ \\
\hline Bolte et al. 2006 & & $\checkmark$ & & 10 & $E$ & $\checkmark$ & $\checkmark$ & & & & & $\checkmark$ & $v$ & $\checkmark$ & & & & $\checkmark$ & & & & & & $\checkmark$ \\
\hline $\begin{array}{l}\text { Bosseler \& } \\
\text { Massaro } 2003 \\
\end{array}$ & & & & 8 & $\mathrm{~L}$ & & & & $\checkmark$ & & & $\checkmark$ & $\checkmark$ & & & & $\checkmark$ & & & $\checkmark$ & & $\checkmark$ & $\checkmark$ & \\
\hline $\begin{array}{l}\text { Clark \& Green } \\
2004\end{array}$ & & & & 2 & $\mathrm{~L}$ & $\checkmark$ & & & $\nu$ & & $\checkmark$ & & $\checkmark$ & & & & & & & & & & & $\checkmark$ \\
\hline Colby 1968 & & $\checkmark$ & & 10 & $\mathrm{~L}$ & & $\checkmark$ & & & & $\boldsymbol{v}$ & $\checkmark$ & & & $\checkmark$ & & $\checkmark$ & & & & & & $\checkmark$ & \\
\hline Colby 1973 & & & & 17 & $\mathrm{~L}$ & & $\checkmark$ & & & & 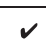 & $\nu$ & & & $\checkmark$ & & $\checkmark$ & & & & & & & $\checkmark$ \\
\hline $\begin{array}{l}\text { Colby \& Kraemer } \\
1975\end{array}$ & & & & 1 & $\mathrm{~L}$ & & 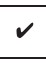 & & & & $v$ & $\checkmark$ & & & $\checkmark$ & & $\checkmark$ & & & & $\checkmark$ & & & $\checkmark$ \\
\hline $\begin{array}{l}\text { DeLeo et al. } \\
2011\end{array}$ & $\checkmark$ & $\checkmark$ & $\checkmark$ & 3 & C & $\checkmark$ & & & $\checkmark$ & $\checkmark$ & $\checkmark$ & & $\checkmark$ & & & $\checkmark$ & & & & & & & $\boldsymbol{v}$ & \\
\hline Faja et al. 2008 & & & & 10 & $\mathrm{~F}$ & $\checkmark$ & $\checkmark$ & & & & & $\checkmark$ & $\checkmark$ & $\checkmark$ & & & $\checkmark$ & & & $\checkmark$ & & & & $\checkmark$ \\
\hline Faja et al. 2011 & & & & 13 & $\mathrm{~F}$ & $\checkmark$ & $\checkmark$ & & & & & $\checkmark$ & $\checkmark$ & $\checkmark$ & & & $v$ & $\checkmark$ & & $\checkmark$ & & & $\checkmark$ & \\
\hline $\begin{array}{l}\text { Golan \& Baron- } \\
\text { Cohen } 2006\end{array}$ & & $\checkmark$ & & 77 & $\mathrm{E}$ & $\checkmark$ & & $\checkmark$ & & & $\boldsymbol{v}$ & $\checkmark$ & $\checkmark$ & $\checkmark$ & & & & & $\checkmark$ & & & & & $\checkmark$ \\
\hline $\begin{array}{l}\text { Grynszpan et al. } \\
2008\end{array}$ & & & & 10 & $\mathrm{~S}$ & $\checkmark$ & & & $\checkmark$ & & $\checkmark$ & & $\boldsymbol{v}$ & & & & & & & & $\checkmark$ & & & $\checkmark$ \\
\hline $\begin{array}{l}\text { Hagiwara \& Myles } \\
1999\end{array}$ & & & $\checkmark$ & 3 & A & & & & $\checkmark$ & & & & & & $\checkmark$ & & & & $\checkmark$ & & & & & $\checkmark$ \\
\hline $\begin{array}{l}\text { Heimann et al. } \\
1995\end{array}$ & & & & 11 & $\mathrm{~L}$ & & & & $\checkmark$ & & & & $\boldsymbol{v}$ & $\checkmark$ & $\checkmark$ & & & & $\checkmark$ & $\checkmark$ & & & & $\checkmark$ \\
\hline $\begin{array}{l}\text { Herrera et al. } \\
2008\end{array}$ & & & & 2 & $S$ & & $\checkmark$ & & & & & & & $\checkmark$ & $\checkmark$ & & $\checkmark$ & & & & & & $\boldsymbol{\nu}$ & \\
\hline $\begin{array}{l}\text { Hetzroni \& } \\
\text { Tannous } 2004\end{array}$ & & & $\checkmark$ & 5 & C & & & & $\checkmark$ & & & $\checkmark$ & & & $\checkmark$ & & & & $\checkmark$ & & 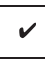 & & $\boldsymbol{\nu}$ & \\
\hline $\begin{array}{l}\text { Hetzroni \& } \\
\text { Shalem } 2005\end{array}$ & $\checkmark$ & & 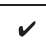 & 6 & $\mathrm{~L}$ & & & & $\boldsymbol{v}$ & & & $\checkmark$ & $\nu$ & & & & $v$ & & & & $v$ & $\boldsymbol{v}$ & $\nu$ & \\
\hline $\begin{array}{l}\text { Hopkins et.al. } \\
2011\end{array}$ & & & & 49 & $S$ & $\checkmark$ & & & $v$ & & & $\boldsymbol{\nu}$ & $v$ & 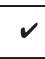 & $v$ & $\boldsymbol{\nu}$ & & & & & & & $\nu$ & \\
\hline $\begin{array}{l}\text { LaCava et al. } \\
2007\end{array}$ & & & & 8 & $\mathrm{E}$ & & & $\checkmark$ & $\boldsymbol{V}$ & & & $\boldsymbol{v}$ & $v$ & & & & & & & & & & & $v$ \\
\hline $\begin{array}{l}\text { LaCava et al. } \\
2010\end{array}$ & & & & 4 & $\mathrm{E}$ & & & & 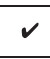 & & $\nu$ & $\nu$ & $\nu$ & $v$ & $\checkmark$ & $\checkmark$ & $\boldsymbol{v}$ & & & & & & $\boldsymbol{\nu}$ & \\
\hline $\begin{array}{l}\text { Massaro \& } \\
\text { Bosseler } 2006\end{array}$ & & & & 5 & $\mathrm{~L}$ & $v$ & & & $\nu$ & & & $v$ & $v$ & & & 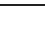 & & & & & $v$ & & & $v$ \\
\hline $\begin{array}{l}\text { Mechling et al. } \\
2009\end{array}$ & $\checkmark$ & & & 3 & A & & & & $\nu$ & & & & & & $\checkmark$ & & & & & $\boldsymbol{V}$ & & $\boldsymbol{\nu}$ & 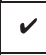 & \\
\hline $\begin{array}{l}\text { Machling \& } \\
\text { Savidge } 2011\end{array}$ & & & $\checkmark$ & 3 & $A$ & & & & $\nu$ & & & & 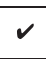 & & $v$ & & & & & $\nu$ & & & & $\checkmark$ \\
\hline $\begin{array}{l}\text { Miller \& Neuringer } \\
2000\end{array}$ & $v$ & & & 5 & 0 & & & $v$ & & & $\nu$ & $v$ & $v$ & & & $v$ & & & & & & & $v$ & \\
\hline $\begin{array}{l}\text { Mitchell et al. } \\
2007\end{array}$ & & & & 6 & $S$ & $\nu$ & $\nu$ & & & & $v$ & & & & 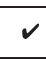 & & & & & & & & & $\checkmark$ \\
\hline $\begin{array}{l}\text { Moore \& Calvert } \\
2000\end{array}$ & & & & 14 & $\mathrm{~L}$ & $\nu$ & & & $\nu$ & & & $v$ & & & & & $v$ & & $\boldsymbol{v}$ & $v$ & & & $\nu$ & \\
\hline $\begin{array}{l}\text { Moore et al. } \\
2005\end{array}$ & & & $\checkmark$ & 34 & $E$ & & & $v$ & & & & $\boldsymbol{v}$ & $v$ & & & $\boldsymbol{V}$ & & & & $\boldsymbol{v}$ & & & & $v$ \\
\hline $\begin{array}{l}\text { Parsons et al. } \\
2004\end{array}$ & & $\nu$ & & 12 & $\mathrm{~S}$ & $v$ & $\boldsymbol{v}$ & & & & & & & & $\boldsymbol{v}$ & & $v$ & & & $\nu$ & & & & $v$ \\
\hline $\begin{array}{l}\text { Parsons et al. } \\
2005\end{array}$ & & & & 12 & $S$ & $\nu$ & $\boldsymbol{v}$ & & & & & & & & $\nu$ & & & & & $\boldsymbol{v}$ & & & & $v$ \\
\hline $\begin{array}{l}\text { Parsons et al. } \\
2006\end{array}$ & $v$ & & $\checkmark$ & 2 & $S$ & & $\nu$ & & & & & & & & $v$ & & & & & $\boldsymbol{v}$ & & $\boldsymbol{v}$ & & $v$ \\
\hline $\begin{array}{l}\text { Rajendran \& } \\
\text { Mitchell } 2000\end{array}$ & & & & 2 & $S$ & $\nu$ & & $v$ & & & & & & $\boldsymbol{\nu}$ & & $v$ & & & & $\boldsymbol{v}$ & & & & $v$ \\
\hline $\begin{array}{l}\text { Schwartz et al. } \\
2010\end{array}$ & & $v$ & & 20 & 0 & $\boldsymbol{v}$ & $\nu$ & & & & & & & $\boldsymbol{\nu}$ & & $\checkmark$ & & & & 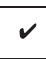 & & & & $\checkmark$ \\
\hline $\begin{array}{l}\text { Self et al. } \\
2007\end{array}$ & & & & 8 & A & $v$ & & & $\nu$ & & & & $\boldsymbol{v}$ & & $\nu$ & & & & & & $\checkmark$ & & $\nu$ & \\
\hline $\begin{array}{l}\text { Silver \& Oakes } \\
2001\end{array}$ & & & & 22 & $E$ & $v$ & & & $\boldsymbol{v}$ & & & $\checkmark$ & $\boldsymbol{v}$ & $\boldsymbol{\nu}$ & & & & & $\boldsymbol{v}$ & & & & $\boldsymbol{v}$ & \\
\hline
\end{tabular}


Table 1 (Continued)

\begin{tabular}{|c|c|c|c|c|c|c|c|c|c|c|c|c|c|c|c|c|c|c|c|c|c|c|c|c|}
\hline & \multicolumn{3}{|c|}{ Design } & \multicolumn{3}{|c|}{ Methods } & \multicolumn{6}{|c|}{ Implementation } & \multicolumn{10}{|c|}{ Evaluation } & \multicolumn{2}{|c|}{ Findings } \\
\hline & $\begin{array}{l}\frac{5}{0} \\
\text { की } \\
\frac{1}{0} \\
\dot{0} \\
0\end{array}$ & 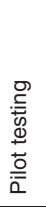 & 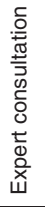 & $z^{\prime \prime}$ & 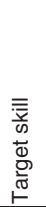 & 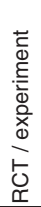 & 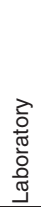 & $\begin{array}{l}\stackrel{\oplus}{E} \\
\text { 온 }\end{array}$ & $\begin{array}{l}\overline{0} \\
\overline{0} \\
\bar{c} \\
\text { d }\end{array}$ & $\begin{array}{l}\frac{0}{\overline{0}} \\
\frac{0}{\mathrm{~g}} \\
\frac{0}{0} \\
\frac{0}{\frac{0}{E}} \\
\frac{3}{\Sigma}\end{array}$ & 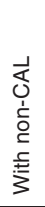 & 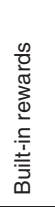 & 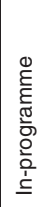 & 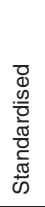 & 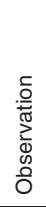 & 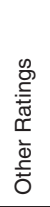 & 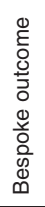 & 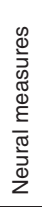 & 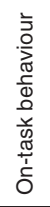 & 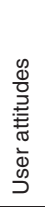 & 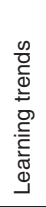 & 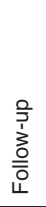 & $\begin{array}{l}\stackrel{D}{D} \\
\stackrel{D}{0} \\
0\end{array}$ & $\begin{array}{l}\bar{D} \\
\stackrel{\otimes}{ \pm} \\
\stackrel{x}{\Sigma}\end{array}$ \\
\hline $\begin{array}{l}\text { Strickland et al. } \\
1996\end{array}$ & & & & 2 & O & & $\checkmark$ & & & & & & & & $\checkmark$ & & & & & $\checkmark$ & & & $\checkmark$ & \\
\hline $\begin{array}{l}\text { Strickland et al. } \\
2007\end{array}$ & & $\checkmark$ & & - & $A$ & & & & & & & & & & $\boldsymbol{v}$ & & & & & $\checkmark$ & & & $\checkmark$ & \\
\hline $\begin{array}{l}\text { Sugasawara \& } \\
\text { Yamamoto } 2007\end{array}$ & & & & 1 & $\mathrm{~L}$ & & & $\checkmark$ & & & & $\checkmark$ & & & $\checkmark$ & & & & & & & & $\checkmark$ & \\
\hline $\begin{array}{l}\text { Swettenham } \\
1996\end{array}$ & & & & 8 & $S$ & $\checkmark$ & $\checkmark$ & & & & $\checkmark$ & $\boldsymbol{v}$ & $\checkmark$ & & & & $\checkmark$ & & & & & $\checkmark$ & & $\checkmark$ \\
\hline $\begin{array}{l}\text { Tanaka et al. } \\
2010\end{array}$ & & & & 79 & $\mathrm{~F}$ & $\checkmark$ & & $\checkmark$ & & & $\checkmark$ & $\checkmark$ & $\checkmark$ & & & & & & & & & & $\checkmark$ & \\
\hline Tjus et al. 2001 & & & & 11 & $\mathrm{~L}$ & $\checkmark$ & & & $\checkmark$ & & $\checkmark$ & & & & $\checkmark$ & & $\checkmark$ & & $\checkmark$ & $\checkmark$ & & & $\checkmark$ & \\
\hline Tjus et al. 1998 & & & & 13 & $\mathrm{~L}$ & & & & $\checkmark$ & & & $\checkmark$ & $\checkmark$ & $\checkmark$ & & & $\checkmark$ & & & & & $\boldsymbol{v}$ & $\checkmark$ & \\
\hline $\begin{array}{l}\text { Trepagnier et al, } \\
2006\end{array}$ & & $\checkmark$ & & - & $S$ & & $\checkmark$ & & & & & $\checkmark$ & & & $\checkmark$ & & & & & & & & $\checkmark$ & \\
\hline $\begin{array}{l}\text { Trepagnier et al } \\
2011\end{array}$ & & $\checkmark$ & $\checkmark$ & 16 & $\mathrm{C}$ & & & $\checkmark$ & & & & $\checkmark$ & $\checkmark$ & & & & & & & $\checkmark$ & & & $\checkmark$ & \\
\hline $\begin{array}{l}\text { Wallace et al. } \\
2010\end{array}$ & & & & 10 & 0 & $\checkmark$ & $\checkmark$ & & & & & & & & $\checkmark$ & $\checkmark$ & & & & $\checkmark$ & & & $\checkmark$ & \\
\hline $\begin{array}{l}\text { Whalen et al. } \\
2010\end{array}$ & & & & 47 & $\mathrm{~S}$ & $\checkmark$ & & & $\checkmark$ & & $\checkmark$ & $\checkmark$ & $\checkmark$ & $\checkmark$ & & & & & & & & & & $\checkmark$ \\
\hline $\begin{array}{l}\text { Williams et al. } \\
2002\end{array}$ & $\checkmark$ & & $\checkmark$ & 8 & $\mathrm{~L}$ & $\checkmark$ & & & $\checkmark$ & & $\boldsymbol{\nu}$ & $\checkmark$ & & $\checkmark$ & $\boldsymbol{V}$ & $\checkmark$ & $\checkmark$ & & $\nu$ & & & & $\checkmark$ & \\
\hline $\begin{array}{l}\text { Yamamoto \& } \\
\text { Miya, } 1999\end{array}$ & & & & 3 & $\mathrm{~L}$ & & $\checkmark$ & & & & $\boldsymbol{v}$ & $\nu$ & & & $\boldsymbol{V}$ & & $\checkmark$ & & & & & $\nu$ & & $\checkmark$ \\
\hline
\end{tabular}

Notes on table categories: a tick indicates that in the cited study this aspect is reported

$A$ adaptive behaviours/life skills, $C$ communication, $E$ emotion recognition, $F$ face recognition, $L$ literacy, $S$ social, $O$ other, $C o$-design working with end users during the design process, Expert consultation working with teachers, parents or practitioners during design, With non-CAL where technology is combined with a non-computerised element, usually tutoring during CAL sessions, or real world rewards, Findings are categorized as positive or mixed because no negative results are reported

project and yet a minority provide any detail at all on the design process for those technologies. Poorly designed CAL may result in a lack of learning which unfairly suggests that CAL itself is a poor educational method and so it is essential to ensure highest quality in design. Opportunities to share good practice in design are lacking, for example in psychological journals publishing principally experimental studies.

\section{Should Autism Technology Be Autism Specific?}

The vast majority of papers included in this review report on the use of software which they have designed themselves for specific use with children with autism with only a handful of exceptions (Bernard-Opitz et al. 1999; Heimann et al. 1995). Very few give any detail on the design process and how the final version described in the report was developed. Participatory design is considered to represent best practice when designing for any group outside the mainstream (Guha et al. 2012), including children or individuals with restricted communication abilities (Frauenberger, et al. 2011). In addition, good practice in design for autism should include consultation with parents and/or relevant professionals (e.g. teachers, speech and language therapists and clinical psychologists) (Porayska-Pomsta et al. 2011).
Some groups of authors do report on co-design processes (De Leo et al. 2011), expert consultation (Hetzroni and Shalem 2005) or pilot testing of beta-versions of the software (Beaumont and Sofronoff 2008; Tjus et al. 1998; Strickland et al. 2007). It is assumed that this design and re-design process should increase the efficacy of the final product, particularly influencing the player's motivation and consequently their learning. However, there is currently no systematic comparison of technologies developed with or without this input and so it is not possible to draw a firm conclusion about the impact of participatory design, expert consultation or pilot testing on learning outcomes.

\section{Is Personalisation Important?}

One way to cast light on the requirement for user involvement in design is to consider the added value provided by personalisable features in technology. One group of authors published a series of reports looking at language acquisition among children with ASD and other groups, using two different programs: Alpha (Heimann et al. 1995; Tjus et al. 2001) and DeltaMessages (Tjus et al. 1998). In this latter paper they specifically state that DeltaMessages was designed to be a "more flexible and motivating tool" (p.141). DeltaMessages 
included options to select the mode of presentation of new words (e.g. graphics and audio) including the possibility of combining modes. This permits application of a single CAL approach to children with differing baseline language abilities. In this final study the authors report no dropout at all from their sample of 13 children, and attribute this to the greater child control over learning offered by the flexibility of the new program.

Hagiwara and Myles (1999) likewise emphasise the value of personalisation in a study using computer-based social stories to support learning of real-world skills in three boys with ASD. Social stories interventions are known to be most beneficial when they are created for individual children with bespoke images and text (Gray and Garand 1993). One possibility raised in this study is that using technology is a particularly effective way of delivering this personalisation.

\section{What Content Should Be Included in Good CAL?}

Authors in this field are wary of the accusation that technological supports provide only "bells and whistles" without significantly enhancing learning or outcome. However, the proliferation of multimedia content indicates that there may be a role for these CAL features in education and therapy. Moore and Calvert (2000) claim that the multimedia content of a program created to teach new vocabulary "enabled children to embed the practice of new skills within the natural context, be it social or academic, of these skills" (p.20). They cite evidence of a direct relationship between attention to the program and learning, illustrating how the attention-getting features of CAL may enhance user outcomes.

Other authors also emphasise the value of multi-media content (Colby 1968; Hagiwara and Myles 1999; Rehfeldt et al. 2004; Stromer et al. 2006; Williams et al. 2002) and specifically graphics (Bernard-Opitz et al. 1999; Massaro and Bosseler 2006; Hopkins et al. 2011; Moore et al. 2005; Tjus et al. 2001). In particular, when working with younger children or those with limited or no verbal language, being able to present attractive, engaging, audio content with animation is considered an advantage over traditional teaching methods (e.g. Basil and Reyes 2003). However, these reports should be contrasted against a single, but methodologically rigorous finding that enriched multi-media content may not facilitate learning for people with ASD (Grynszpan et al. 2008).

Massaro and Bosseler (2006) have conducted the only identified study which explores the impact of a single design feature on learning outcome, concluding that tutoring language is more effective with an animated face than without. An attempt to systematically link features of CAL to preferences of users failed to reveal consistent patterns of preferences across participants, and was hampered by missing data (Lahm 1996).

At a more detailed level, there is little information about the appropriate graphic style of CAL for autism. For example, it is common for cartoon characters for pre-schoolers to have unnaturally large eyes but it may be that when designing for children with ASD eyes should be at a more realistic scale in the face to minimise the potential for gaze-aversion (Kylliainen and Hietanen 2006). The use of animations versus static graphics has rarely been explored. It is known that individuals with ASD may process motion atypically at a very low perceptual level (Jarrold and Scott-Samuel 2005) and may react atypically to biological motion (Blake et al. 2003). Therefore the use of motion - traditionally thought to capture attention - may need to be examined for this population.

Another factor is whether visual content should represent real life (e.g. photos and video) or can be cartoon-like. Eye-tracking studies with children with ASD have shown that visual scanning may be more typical for simplified, rather than complex stimuli (Kemner et al. 2007; Speer et al. 2007). If the goal of the software is to enhance face perception or emotion recognition skills, then the use of real faces may be justified. But if faces are incidental to the learning outcome - e.g. when a child is required to interact with an on-screen character to learn new words - then it may be more appropriate to use line-drawn images.

Where realism is desirable, one way to deliver a more realistic CAL design is to use virtual reality. An objection to virtual reality approaches is that participants with ASD might not treat the virtual world in the same way as the real world (Bellani et al. 2011). Differences have been found between people with ASD and TD counterparts. For example, Parsons and colleagues $(2004,2005,2006)$ found that participants with ASD were more likely to bump into virtual characters, while Schwartz colleagues (Schwartz et al. 2010) reported that a group of people with ASD experienced fewer feelings of involvement when interacting with virtual characters. In each case it is unclear whether these findings derive from the general social impairments associated with autism or whether they are specific to the virtual reality world.

On the other hand, there is evidence that people with ASD do understand the virtual world to be a representation of reality (Parsons et al. 2004; Strickland et al. 1996; Strickland 1997; Wallace et al. 2010) and authors have therefore promoted virtual reality as a way to teach social and play skills which are challenging to rehearse in the real world (Herrera et al. 2008; Mitchell et al. 2007; Moore et al. 2005; Parsons and Mitchell 2002). Virtual worlds benefit from being able to replicate the social world in relative detail and accuracy, yet they also provide a safe environment for the participant to rehearse social interactions repeatedly.

Virtual reality has also been used to support the learning of life skills, such as shopping (Lanyi and Tilinger 2004), safety behaviours in emergencies (Self et al. 2007) and street and fire safety (Strickland et al. 2007). These studies illustrate cases where virtual reality is uniquely placed to offer an opportunity for rehearsal of a skill without the risks associated with a realworld training scenario. There are also proposals to use virtual reality to directly influence neural function, specifically in the 
mirror neuron system, thought to be impaired in autism (Altschuler 2008; Zhu et al. 2011).

\section{How Should Rewards Be Delivered in CAL?}

One clear advantage of using CAL over traditional teaching or therapeutic methods is that regular rewards can be built in to the learning program. For Colby (1973) the opportunity to experience success is a key benefit of CAL when working with young and/or pre-verbal children with ASD. Moore and Calvert (2000) emphasise the importance of immediate contingent reinforcement to maximise attention to the program and attainment of goals - something hard to do in a teacherled classroom but easy to do on a computer. Rewards also present another opportunity to personalise content (BernardOpitz et al. 2001, 1999). In the former study, participating children were able to select from a menu of rewards and the authors report that $61 \%$ of the time children with ASD selected sensory reinforcers, such as animated spirals or lines, compared to only $40 \%$ of the time for typically developing peers. Trepagnier et al. (2006) present a novel form of reward by placing children in a moving airplane ride, which was triggered by a correct response to the computer program. While a sub-set of children did not enjoy the motion, the majority found it highly rewarding.

\section{How Should CAL Be Structured?}

A number of different learning structures have been modelled in CAL studies. Clark and Green (2004) compare an exclusion and a delayed-cue learning procedure and find good learning of new vocabulary across the board, but especially in the delayed-cue condition. Hetzroni and Shalem (2005) use a backwards-fading task to teaching children to recognise the printed name of various branded items, previously recognised by their full logo. Trepagnier et al. (2006) use eye-movement recording to provide rewards contingent on gaze to a correct location, providing a CAL solution to children without any requirement for an active behavioural or verbal response.

Howe (1979) defines learning as the gathering of information, which comes about through activity, motivation being a prerequisite for such activity. Computers are considered in this context to be the ideal learning tool, being equipped with endless information, easily gathered by an actively engaged and highly motivated learner. A common feature of reports on CAL for autism is that computerised approaches provide a valuable opportunity to regulate learning and provide a very consistent, predictable environment to the user (e.g. Colby 1973; Panyan 1984). The key to success in this approach is that changes are made gradually and flagged in advance. CAL provides a perfect opportunity to manage this kind of measured change as it is possible to introduce novel content without making additional modifications. There is even evidence that children with ASD may respond particularly well to changes when introduced in a CAL context (Alcorn et al. 2011).

\section{Design Conclusions}

There is an absence of published data which links design practices and specific CAL features to either learning outcomes or other evaluation metrics such as participant dropout rates. Publications describing best practice in co-design of novel technologies may not always be available to those working in the autism research field, and moreover lack rigorous quantitative data to support claims. And conversely, studies which reveal positive benefits of working with CAL using strong experimental methods rarely provide insight into the development of the technology. Features which may promote better efficacy of CAL include personalisation options, immediate reinforcement, realistic and multi-sensory content and structured learning environments. There are many ways in which the literature on cognitive skills and sensory preferences of people with ASD might further impact on the design of CAL and these literatures should more frequently be consulted in future research.

\section{CAL: Lessons for Implementation}

Implementation here refers to how the CAL approach is situated in the real world both in terms of physical setting, and combination with other non-CAL supports.

\section{What Environments Are Most Appropriate for a CAL Approach?}

The majority of studies included here and in recent reviews have used CAL in a classroom or laboratory setting (see Table 1). This may in part be attributable to the fact that until relatively recently, computer equipment was much more readily available in schools and universities than in homes, and researchers rarely have the funding to provide hardware as well as software to research participants. The benefits of using CAL in a classroom setting are striking with studies reporting eagerness on the part of participants to engage in CAL opportunities (Moore and Calvert 2000; Williams et al. 2002) and high rates of on-task behaviour during CAL lessons (BernardOpitz et al. 1999; Heimann et al. 1995).

One of the reasons that CAL may be so beneficial in this environment is that a teacher cannot provide one-to-one attention to children in the class, whereas a computer program can give direct and immediate feedback to learners. Incorporating artificial intelligence elements so that programs can be responsive to children's learning would further increase this opportunity though there are limited examples of using 
this kind of CAL for children with ASD (for one example see Porayska-Pomsta et al. 2011).

Hagiwara and Myles (1999) emphasise the portability of CAL, so that the same approach can be provided across multiple settings (e.g. school and home) in line with the general educational position that provision should be consistent across settings. Very few studies have explored this possibility (e.g. De Leo et al. 2011) though the rise of mobile technologies will increase the likelihood of this in the future.

CAL has also been delivered in home environments, most often in studies where adults with high-functioning forms of autism are using software independently (e.g. Golan and Baron-Cohen 2006; Moore et al. 2005; Trepagnier et al. 2011). This may raise concerns that technology here could reinforce the social isolation experience by many people with ASD. However, technology can also provide a route to social contact. Online, people with ASD are heavy users of virtual worlds such as Second Life and may find these a way to combine a desire for social contact with a reluctance or difficulty with integrating into real-life social settings (Fusar-Poli et al. 2008; Orsmond and Kuo 2011). More recently, technology has been used at home by younger people, (e.g. Tanaka et al. 2010) providing an example of how adherence data can be collected in CAL intervention studies. There is no clear evidence of how setting can affect outcome but more studies which take technology out of the lab and integrate into the real world would be desirable.

\section{Should CAL Be Combined with Other Approaches?}

Some studies report on the combination of CAL with realworld rewards (Clark and Green 2004; Hagiwara and Myles 1999; Bernard-Opitz et al. 1999; Miller and Neuringer 2000), at odds with the statement that one strength of CAL is the opportunity to provide immediate, integrated positive reinforcement. Furthermore, a large proportion of the reviewed studies report that users were supported by a teacher or experimenter observing the session and often offering instruction or encouragement (see Table 1). This highlights one of the main challenges of delivering CAL to young children or those with limited cognitive and motor skills, as the majority of CAL systems still require understanding of a complex, distant cause and effect relationship: I press this button on the keyboard over here, and something happens on the screen over there.

It could be seen as a criticism of CAL that in order to access learning material children first need to develop the skills required to learn (e.g. Swettenham 1996; Yamamoto and Miya 1999). But of course the same can be said of a child learning to be in a busy classroom, learning to sit still or learning to listen to a teacher. An unknown issue when using CAL with very young and/or intellectually impaired people with ASD is whether learning to use CAL proceeds more rapidly and efficiently than learning to access traditional education. And moreover whether those children who need support to learn to use a computer are then able to benefit sufficiently from CAL content to make the effort worthwhile.

CAL has also been combined with other therapeutic approaches such as social skills groups (Beaumont and Sofronoff 2008; Golan and Baron-Cohen 2006; Whalen et al. 2010) and a personal tutor (LaCava et al. 2007, 2010). These well-designed studies have uniformly reported gains as a result of CAL for emotion recognition and social skills across a range of ages and ability levels. However, even the inclusion of a non-CAL element does not always result in generalisation of the taught skill (e.g. Golan and Baron-Cohen 2006).

\section{Implementation Conclusions}

In this case, conclusions are limited not by a lack of reporting but by a narrowness of approach across the literature. A large proportion of studies are based in classroom or laboratory settings making it hard to establish how else technological supports for learning and treatment might be implemented. With the rise of mobile technologies it is important to update our knowledge in this area by exploring how CAL can be implemented across multiple settings and/or online.

\section{CAL: Lessons for Evaluation}

The use of CAL invites a new approach to evaluation and data collection. First, CAL provides a way to collect large quantities of data to map not just outcomes, but also learning trajectories over time. Second, commercial technologies for education and therapy are developing at a rate with which academia cannot keep pace. Moreover, some technologies which have been developed and evaluated in published research studies are now not available to the public, raising questions about the relevance of their 'proven' efficacy.

\section{What Study Designs Are Most Appropriate for Evaluating CAL?}

While this field lacks substantial evidence from randomised controlled trials, there are signs that this gold standard methodology is becoming more common in recent evaluations of CAL (Beaumont and Sofronoff 2008; Bolte et al. 2002; Bolte et al. 2006; Faja et al. 2008; Faja et al. 2011; Golan and Baron-Cohen 2006; Hopkins et al. 2011; Tanaka et al. 2010). All of these studies with one exception (Beaumont and Sofronoff 2008) report on the use of CAL to teach face or emotion recognition. The use of rigorous experimental methods may be beneficial in helping a piece of CAL technology reach the consumer. Of the studies listed above, four of the six programmes evaluated are now available on the open market. This contrasts with the 
relatively low general rate of publication of CAL for autism as reported elsewhere (Ramdoss et al. 2011a, b, 2012) and may indicate that rigorous research evidence is beneficial in later taking an academic product to market.

Experimental studies are more widely available but these are also accompanied by a large number of case study reports (e.g. De Leo et al. 2011; Hagiwara and Myles 1999; Herrera et al. 2008; Mechling et al. 2009; Mechling and Savidge 2011; Parsons et al. 2006). In addition, some experimental studies lack non-CAL control conditions (Swettenham 1996; Rajendran and Mitchell 2000). While softer evidence is acceptable in a new field of enquiry, the study of autism and technology is now sufficiently established that we can legitimately expect higher quality, quantitative data to be available. One of the challenges to achieving this goal is that evaluation of a specific piece of software risks being out-of-date before publication of the results, due to the rapid rate of progress of commercial technology development. For this reason, it is crucial that CAL research focusses on revealing the specific features of successful CAL so that these findings can be applied to future technological developments. One way to address this outcome is to use in-program data collection to support external outcome measurement, as described below.

\section{How Can CAL Programs Be Harnessed to Provide Enhanced Data Collection?}

From the earliest days of CAL and autism research, it has been suggested that the wealth of data collected by the computer can provide a useful way to model the abilities and learning of people with ASD (Colby and Kraemer 1975). A large number of studies reviewed for this paper report not just on outcome but also on accuracy changes over time and other learning trajectories (see Table 1). Silver and Oakes (2001) provide a good example of this approach in a study which correlated computer game use with outcome. In this way CAL studies have an advantage over interventions delivered by parenttraining or therapists, as they offer a way to record treatment adherence during enrolment in the study. For example, Golan and Baron-Cohen (2006) excluded from their study participants who had not played the MindReading software for a minimum amount of time across the intervention period.

\section{How Can We Reasonably Measure Generalisation from CAL to Other Contexts?}

As well as built-in data collection to model learning processes, CAL often provides an opportunity to measure improvement in the target skill using in-game test conditions (see Table 1). However, particularly when aiming to teach social interactive skills, but also for academic learning, it is desirable that CALtaught skills should also generalise to non-taught domains. It is a consistent problem in intervention studies for autism that generalisation is hard to achieve (Fletcher-Watson and McConachie 2010). When using CAL this issue becomes even more pressing since computer skills are not highly valued in and of themselves.

There is some evidence for successful generalisation of CAL-taught skills to real world settings (Bosseler and Massaro 2003; Hetzroni and Shalem 2005; Hetzroni and Tannous 2004; Colby 1968; Williams et al. 2002; Panyan 1984 ) as well as for sustained gains in follow-up (Beaumont and Sofronoff 2008; Bosseler and Massaro 2003). The degree of generalisation seems important (e.g. Swettenham 1996). Golan and Baron-Cohen (2006) precisely evaluated generalisation to both close and distant tasks in order to provide detailed evidence of the degree of crossover. They found that participants using their MindReading software were able to replicate emotion recognition success in close-generalisation tasks such as measures of emotion recognition using novel content but a similar presentation format. However, there was no evidence for distant generalisation to entirely new test formats.

One way to investigate the impact of CAL is to measure changes at a neural level. Studies have used both event-related potentials (Faja et al. 2011) and fMRI data (Bolte et al. 2002) to explore whether CAL can induce profound changes in the brain. The former study revealed an impact of training on brain activity but this was not observed in the latter, fMRI study.

\section{How Can We Evaluate the Indirect Benefits of Using CAL?}

Experimental designs may not capture some of the most valuable benefits of using CAL which relate not to learning outcome, but instead to participant behaviour and well-being, family or classroom context and economic value. A number of studies report improvements in participant behaviour when working with CAL (Bernard-Opitz et al. 1999; Moore and Calvert 2000; Williams et al. 2002). Furthermore, the opportunity to work with an exciting piece of technology and to demonstrate success may provide much-needed peer respect and well-being to a person with ASD. This potential benefit of technology is under-studied, though there are direct reports of adults with ASD finding CAL supports enjoyable to use (Rajendran and Mitchell 2000; Trepagnier et al. 2011) and of mothers rating the value of CAL highly (Bernard-Opitz et al. 1999). Of course, the statement that people with ASD enjoy learning with computers is a generalisation and there is evidence of significant drop-out from some CAL studies (e.g. Heimann et al. 1995; Golan and Baron-Cohen 2006; Silver and Oakes 2001) while in others some children lack the skills necessary to access the technology (Whalen et al. 2010). Further study is needed to establish whether there is a consistent behavioural or symptom profile associated with preference for CAL, or associated with success in learning this way.

As previously mentioned, a common concern is that working with technology will decrease opportunities for social 
interaction. However, at least in a classroom setting, there is evidence that CAL can provide an opportunity to foster social communication (Bernard-Opitz et al. 1999; Tjus et al. 2001; Heimann et al. 1995; Hetzroni and Shalem 2005; Williams et al. 2002). One way to address these concerns is to explore further the links between user profiles and technology use (e.g. Parsons et al. 2004, 2005, 2006; Rajendran and Mitchell 2000; Tjus et al. 1998, 2001) in order to match specific technologies to the needs and preference of the user.

Finally, it is worth highlighting the economic argument for CAL (Whalen et al. 2010). While computer technology is often thought of as an expensive luxury, especially the most recent developments, the cost dwindles into insignificance when compared with expense of one-to-one learning support, expert therapist time or even high-quality parent training. While technology should not be supposed to replace any of these valuable ways to provide education and intervention for people with ASD, technology may provide a way to add a daily dose of complimentary content which reinforces expert-led interventions. This may be particularly useful where resources are scarce and direct contact hard to achieve, such as in rural communities. Moreover, technology can provide a method for making intervention and education available internationally, to the benefit of the worldwide autism community.

\section{Evaluation Conclusions}

There is evidence that research evidence in this field is becoming more rigorous with an increase in RCT designs. CAL provides a potentially enormous benefit in permitting ongoing data collection across a period of learning, rather than just focus on start and end point scores, and this has been widely exploited in published studies. Evaluation should include measurement of learning outcomes but also associated variables such as amount of on-task behaviour, participant enjoyment and confidence, teacher or parent acceptability, drop-out rates and economic data.

\section{Using New Technologies}

Recent advances are beginning to change the face of technology-enhanced learning. In particular, the proliferation of the web (Jordan 2010), online gaming (Wilkinson et al. 2008), virtual worlds such as Second Life (Fusar-Poli et al. 2008), the rise of mobile devices such as Smartphones and the now wide-spread use of touchscreen technology invites new ways of thinking about education and support for people with autism spectrum disorders.

In an early example of this work, Bishop (2003) reports on the use of a mobile phone application called PARLE (Portable Affect Reference Learning Environment) which can be used to translate confusing language such as metaphors into simpler versions. Users found the programme easy, useful and efficient in an experimental test of the software, though so far there are no reports of its use in the real world. In a similar project, De Leo and colleagues (2011) report on the development of a Smartphone app version of the Picture Exchange Communication System (PECS: Bondy and Frost 2001) to support communication for children with autism. Case studies indicate that this PixTalk software can be incorporated into on-going therapy though it is not clear whether PixTalk can support language learning in the same way that PECS does. Mechling and colleagues have successfully trialled use of a personal digital assistant to support both abstract and real world skills using step-by-step prompts (Mechling et al. 2009; Mechling and Savidge 2011). iPads may also provide a new way to deliver intervention to young children or those with severe intellectual disabilities (Kagohara et al. 2013) and this is being explored in an on-going randomised controlled trial of a novel app to develop social attention skills (FletcherWatson et al. 2013)

\section{Discussion}

A wide-range of CAL approaches has been developed specifically for the use of people with ASD. This approach to education, therapy and support regularly shows an advantage of CAL over traditional teaching methods, though rigorous experimental evidence remains in limited supply. CAL has been used to support traditional academic learning (e.g. vocabulary, grammar, reading and mathematics); social skill development, life skill development and to reduce challenging behaviours. CAL provides a lot more than just 'bells and whistles' to the education and treatment of people with ASD. The approach seems to foster increased concentration and motivation, by appealing to the common preferences and skill sets of a majority of people with ASD. There are hints that spin-off benefits may include a sense of achievement, confidence, increased peer group status and-perhaps resulting from these-increases in social communication.

Despite the proliferation of publications on CAL and autism, including a number of recent review papers, there remains an absence of a consistent methodology for creating new technologies, implementing these in the home or classroom and evaluating their efficacy. This review has collected evidence over more than four decades of research in CAL for autism and explored whether we can extract from these publications a model for best practice in the field.

Conclusions for Best Practice in CAL Design, Implementation and Evaluation

Published studies on the use of CAL with people with ASD rarely describe the design of the technology under inspection 
and thus one straightforward goal is that authors in future should aim to report on this process. Developing novel software for an atypical group with specialist requirements necessitates collaboration across disciplinary borders and consultation with end-users. Practitioners with a background in participatory design emphasise the importance of including users not just to test early versions of a new program, but in the earliest stages of design. Psychologists and computerscientists have much to learn from these examples of innovative ways of helping those without technological expertise, and often without language, to participate in the design process. Further research should explore whether co-designed programs out-perform those created by professionals alone. It is possible that both types of CAL might deliver good educational content but that participatory design can enhance motivation or reduce drop-out thus expanding the impact of the technology.

CAL studies report in the majority of cases on technologies used in classroom settings or in the lab. As computers become more and more common in the home, and as increasing numbers of people have access to mobile computing via smartphones and tablets, further research is needed to explore how CAL can be implemented across settings. Combining CAL with non-technology intervention components such as social skills groups or tutoring may lead to better outcomes, and has been used most widely when the target skill is in the interpersonal domain. This highlights the limitation of CAL for teaching social content, but also illustrates how expensive expert intervention can be supported by a daily dose of further learning materials via a computer. One oft-cited strength of CAL is the opportunity to provide immediate feedback to the user, helping to motivate and increase focus. Use of real-world reinforcers (such as sweets) may however be useful when the first challenge is to help the user engage with the hardware at all. This occurrence should not necessarily be seen as a disadvantage of CAL because many children unable to access a computer interface may also struggle to take in learning in traditional settings. This is an area where touchscreen and tangible technologies may be of particular value in bringing CAL to very young children and/or those with limited intellectual capacities.

As in all fields of psychology, the experimental method and randomised controlled trials for interventions represent the gold standard in evaluation of CAL. A small but highquality group of studies indicate that it is feasible to apply this method to CAL and that, possibly, using a randomised controlled design may facilitate publication of a piece of software on the commercial stage. Studies should more fully exploit the value of CAL in permitting collection of data across time, and not just at pre- and post-intervention sessions, so that we can explore how learning develops over time and link this with other external measures. The focus of studies, especially when these are evaluating commercial products, should be on exploring how specific CAL features impact on outcome so that those with the most value can be replicated in future technologies. Generalisation may be a challenge for CAL interventions as is it across the autism intervention literature; the best studies delve into this construct by measuring both close and distant generalisation or by combining CAL with other therapeutic methods. Studies in CAL and autism should also incorporate measures of indirect benefits both to the user and those around them (e.g. family members, classmates and teachers) in order to provide a more comprehensive evaluation of the application of CAL in real life.

\section{Future Directions in Research on CAL for Autism}

Parents and teachers are increasingly taking matters into their own hands in selecting and applying technology in the home and classroom. While a device such as an iPad carries a considerable price tag, once purchased the user has access to hundreds of low-priced apps being marketed for people with autism, and thousands more which may also be appealing. Others such as augmented and aided communication apps like Proloquo2Go or Speak4Yourself are priced more highly but come with the promise of giving a nonverbal person with autism a voice. In this context, research can no longer afford to focus on whether CAL is beneficial for a person with ASD and instead needs to find ways of directing families and practitioners towards the best available technologies and guiding them to be used in the best possible ways. Information about questions such as whether autism-specific technologies are better than 'mainstream' alternatives, or how much time playing on a computer is appropriate for a child or young person needs to be based on research evidence and communicated to the community.

Issues of inclusivity are also in the foreground when one considers the real-world application of CAL. One might assume that best practice would be to make beneficial technologies available for free, but that may also mean that they are unsupported. For a technology to be useful, users also need somewhere to go for troubleshooting support and software needs upgrading as operating systems are updated. This may be particularly the case when creating technologies for adolescents and adults, where one common goal across technologies must be to foster independence and selfdetermination. Technologies for this group are thin on the ground, and discussion with families and practitioners suggests that adults with learning disability are expected to make do with technologies designed with pre-schoolers in mind.

New technologies are helping to break down some of the objections to CAL. Complaints that CAL can only be delivered effectively in schools with lots of computers, or that there is a lower ability limit on who can benefit from CAL are being eroded by technology-enhanced approaches 
(e.g. Whalen et al. 2010) including the use of accessible touchscreen interfaces. Mobile devices and internet technology can all be exploited to support people with ASD across settings and in the community. It is also straightforward to update mobile apps or web-based supports regularly to add new content, fix bugs and respond to user feedback. Researchers in the CAL field are developing new approaches, building on the examples of existing CAL and utilising this latest hardware, though few findings in this area have been published.

\section{Summary}

Technology-enhanced learning has been used successfully to promote enhanced learning of new academic, social and life skills in people with autism spectrum disorders from primary school to adulthood. The approach is suited both to the common preferences and skill sets of people with ASD, giving them a chance to demonstrate their abilities and gain peer respect. The field of CAL and autism research may now be maturing. Increasing quantity of publications on the topic is being accompanied by an increase in well-designed experimental studies including a handful of randomised controlled trials. To accompany this growth in size and stature, the field requires a better methodological and theoretical foundation. It is challenging to extract information about design and implementation from studies which focus on reporting learning outcomes, but more work must provide detail on these elements as well as trying to link CAL success with specific features which can be replicated in future. Likewise, evaluation of CAL must encompass indirect effects as well as changes in the target skill.

As well as improving the evidence base, future endeavour in this field must focus on creating high-quality products which can be accessed by the community that needs them. Nevertheless, it must always be acknowledged that the goal for a person with ASD is to allow them to function happily and effectively in our inevitably social, interpersonal world. This means developing flexible responses to changing situations, rather than following rigidly rehearsed rules. For this reason, CAL should always be just one tool in the box of supports for people with ASD.

\section{References}

Alcorn, A., Pain, H., Rajendran, G., Smith, T., Lemon, O., PorayskaPomsta, K., et al. (2011). Social communication between virtual characters and children with autism. Artificial Intelligence in Education, 6738, 7-14.

Altschuler, E. L. (2008). Play with online virtual pets as a method to improve mirror neuron and real world functioning in autistic children. Medical Hypotheses, 70(4), 748-749.
Barakova, E., Gillessen, J., \& Feijis, L. (2009). Social training of autistic children with interactive intelligent agents. Journal of Integrative Neuroscience, 8(1), 23-34.

Basil, C., \& Reyes, S. (2003). Acquisition of literacy skills by children with severe disability. Child Language Teaching and Therapy, 19, $27-48$.

Beaumont, R., \& Sofronoff, K. (2008). A multi-component social skills intervention for children with Asperger syndrome: The Junior Detective Training Program. Journal of Child Psychology and Psychiatry, 49(7), 743-753.

Bellani, M., Fornasari, L., Chattaro, L., \& Brambilla, P. (2011). Virtual reality in autism: state of the art. Epidemiological and Psychiatric Science, 20(3), 235-238.

Bernard-Opitz, V., Sriram, N., \& Sapuan, S. (1999). Enhancing vocal imitations in children with autism using the IBM speech viewer. Autism, 3(2), 131-147.

Bernard-Opitz, V., Sriram, N., \& Nakhoda-Sapuan, S. (2001). Enhacing social problem solving in children with autism and normal children though computer-assisted instruction. Journal of Autism and Developmental Disorders, 31(4), 377-384.

Bishop, J. (2003). The Internet for educating individuals with social impairments. Journal of Computer Assisted Learning, 19, 546-556.

Blake, R., Turner, L. M., Smoski, M. J., Pozdol, S. L., \& Stone, W. (2003). Visual recognition of biological motion is impaired in children with autism. Psychological Science, 14, 151-157.

Blishak, D. M., \& Schlosser, R. W. (2003). Use of technology to support independent spelling by students with autism. Topics in Language Disorders, 23(4), 293-304.

Bolte, S., Feineis-Matthews, S., Leber, S., Dierks, T., Hubl, D. \& Poutska, F. (2002). The development and evaluation of a computer-based program to test and to teach the recognition of facial affect. International Journal of Circumpolar Health 61(Supplement 2): 61-68.

Bolte, S., Hubl, D., Feineir-Matthes, S., Prvulovic, D., Dierks, T., \& Poutska, F. (2006). Facial affects recognition training in autism: can we animate the fusiform gyrus? Behavioural Neuroscience, 120(1), 211-216.

Bondy, A., \& Frost, L. (2001). The picture exchange communication system. Behaviour Modification, 25(5), 725-744.

Bosseler, A., \& Massaro, D. W. (2003). Development and evaluation of a computer-animated tutor for vocabulary and language learning in children with autism. Journal of Autism and Developmental Disorders, 33, 653-672.

Clark, K. M., \& Green, G. (2004). Comparison of two procedures for teaching dictated-word/symbol relations to learners with autism. Journal of Applied Behaviour Analysis, 37, 503-507.

Cobb, S., Beardon, L., Eastgate, R., Glover, T., Kerr, S., Neale, H., et al. (2002). Applied virtual environments to support learning of social interaction skills in users with Asperger's syndrome. Digital Creativity, 31(1), 11-22.

Colby, K. M. (1968). Computer-aided language development in nonspeaking children. Archives of General Psychiatry, 19, 641-651.

Colby, K. M. (1973). The rationale for computer based treatment of language difficulties in nonspeaking autistic children. Journal of Autism and Childhood Schizophrenia, 3(3), 254-260.

Colby, K. M., \& Kraemer, H. C. (1975). An objective measurement of nonspeaking children's performance with a computer-controlled program for the stimulation of language behaviour. Journal of Autism and Childhood Schizophrenia, 5(2), 139-146.

Coleman-Martin, B., Heller, K. W., Cihak, D. F., \& Irvine, K. L. (2005). Using computer-assisted instruction and the nonverbal reading approach to teach word identification. Focus on Autism and Developmental Disabilities, 20(2), 80-90.

Dautenhahn, K., Nehaniv, C. L., Walters, M. L., Robins, B., Kose-Bagci, H., Mirza, A., et al. (2009). KASPAR - a minimally expressive humanoid robot for human-robot interaction research. Applied Bionics and Biomechanics, 6(3-4), 369-397. 
De Leo, G., Gonzales, C. H., Battgiri, P., \& Leroy, G. (2011). A smartphone application and a companion website for the improvement of the communication skills of children with autism: clinical rationale, technical development and preliminary results. Journal of Medical Systems, 35, 703-711.

Delano, M. E. (2007). Video modelling interventions for individuals with autism. Remedial and Special Education, 28, 33-42.

Faja, S., Aylward, E., Bernier, R., \& Dawson, G. (2008). Becoming a face expert: a computerized face-training program for high-functioning individuals with autism spectrum disorders. Developmental Neuropsychology, 33(1), 1-24.

Faja, S., Webb, S., Jones, E. A., Merkle, K., Kamara, D., Bavaro, J., et al. (2011). The effects of face expertise training on hte behavioural performance and brain activity of adults with high functioning autism spectrum disorders. Journal of Autism \& Developmental Disorders, 42(2), 278-293.

Farr, W., Yuill, N., \& Raffle, H. (2010). Social benefits of a tangible user interface for children with autistic spectrum conditions. Autism, 14(3), 237-252.

Fletcher-Watson, S., Hammond, S., O’Hare, A., Pain, H., Petrou, A., \& McConachie, H. (2013). Evaluating the impact of an iPad app on social communicative abilities in young children with autism. San Sebastian: International Meeting for Autism Research.

Fletcher-Watson, S. \& McConachie, H. (2010). Interventions based on the 'Theory of Mind' cognitive model for autism spectrum disorder (Protocol). Cochrane Database of Systematic Reviews: Protocols, 2010, 10. doi:10.1002/14651858. CD008785.

Frauenberger, C., Good, J., \& Keay-Bright, W. (2011). Designing technology for children with special needs: briding perspectives through participatory design. CoDesign, 7(1), 1-28.

Frauenberger, C., Good, J., Alcorn, A., \& Pain, H. (2013). Conversing through and about technologies: Design critique as an opportunity to engage children with autism and broaden research(er) perspectives. International Journal of Child-Computer Interaction. doi:10.1016/ j.ijcci.2013.02.001.

Fusar-Poli, P., Cortesi, M., Borgwardt, S., \& Politi, P. (2008). Second life virtual world: a heaven for autistic people? Medical Hypotheses, $71(6), 980-981$.

Giannopulu, I., \& Pradel, G. (2010). Multimodal interactions in free game play of children with autism and a mobile toy robot. NeuroRehabilitation, 27(4), 305-311.

Golan, O., \& Baron-Cohen, S. (2006). Systemizing empathy: teaching adults with Asperger syndrome or high-functioning autism to recognise complex emotions using interactive multimedia. Development and Psychopathology, 18, 591-617.

Goldsmith, T. R., \& LeBlanc, L. A. (2004). Use of technology in interventions for children with autism. Journal of Early Intensive Behavioural Intervention, 1(2), 166-178.

Gray, C. A., \& Garand, J. D. (1993). Social stories: improving responses of students with autism with accurate social information. Focus on Autism and other developmental disabilities, 8(1), 1-10.

Grynszpan, O., Martin, J.-C., \& Nadel, J. (2008). Multimedia interfaces for users with high functioning autism: an empirical investigation. International Journal of Human-Computer Studies, 66(8), 628-639.

Grynszpan, O., Weiss, P. L., Perez-Diaz, F., \& Gal, E. (2013). Innovative technology-based interventions for autism spectrum disorders: a meta-analysis. Autism. doi:10.1177/1362361313476767.

Guha, M. L., Druin, A., \& Fails, J. A. (2012). Cooperative inquiry revisited: reflections of the past and guidelines for the future of intergenerational co-design. International Journal of ChildComputer Interaction

Hagiwara, T., \& Myles, B. S. (1999). A multimedia social story intervention: teaching skills to children with autism. Focus on Autism and Other Developmental Disabilities, 14(2), 82-95.

Heimann, M., Nelson, K. E., Tjus, T., \& Gillberg, C. (1995). Increasing reading and communication skills in children with autism through an interactive multimedia computer program. Journal of Autism and Developmental Disorders, 25(5), 459-480.

Herrera, G., Alcantud, F., Jordan, R., Blanquer, A., Labajo, G., \& DePablo, C. (2008). Development of symbolic play through the use of virtual reality tools in children with autistic spectrum disorders. Autism, 12(2), 143-157.

Hetzroni, O. E., \& Shalem, U. (2005). From logos to orthographic symbols: a multilevel fading computer program for teaching nonverbal children with autism. Focus on Autism and Other Developmental Disabilities, 20(4), 201-212.

Hetzroni, O. E., \& Tannous, J. (2004). Effects of a computer-based intervention program on the communicative functions of children with autism. Journal of Autism and Developmental Disorders, 34(2), 95-113.

Hopkins, I. M., Gower, M. W., Perez, T. A., Smith, D. S., Amthor, F. R., Casey-Wimsatt, F., et al. (2011). Avatar Assistant: improving social skills in students with an ASD through a computer-based intervention. Journal of Autism \& Developmental Disorders, 41, 15431555.

Howe, J. A. M. (1979). A new deal? Using computers to teach children with communication difficulties. McGill Journal of Education, 14(3), 343-352.

Ijichi, S., \& Ijichi, N. (2007). Computerized lifelong mentoring support using robot for autistic individuals. Medical Hypotheses, 68(3), 493-498.

Jarrold, C., \& Scott-Samuel, N. E. (2005). Motion perception in autism spectrum disorder: we'll move forward once the data become more coherent. Current Psychology of Cognition, 23(1-2), 122-131.

Jordan, C. J. (2010). Evolution of autism support and understanding via and world wide web. Intellectual and Developmental Disabilities, 48(3), 220-227.

Kagohara, D. M., van der Meer, L., Ramdoss, S., O'Reilly, M., Lancioni, G., Davis, T., et al. (2013). Using iPods and iPads in teaching programs for individuals with developmental disabilities: a systematic review. Research in Developmental Disabilities, 34, $147-156$.

Kemner, C., Van der Geest, J. N., Verbaten, M. N., \& Van Engeland, H. (2007). Effects of object complexity and type on the gaze behavior of children with pervasive developmental disorder. Brain and Cognition, 65, 107-111.

Kylliainen, A., \& Hietanen, J. K. (2006). Skin conductance responses to another person's gaze in children with autism. Journal of Autism and Developmental Disorders, 36(4), 517-525.

LaCava, P. G., Golan, O., Baron-Cohen, S., \& Smith Myles, B. (2007). Using assistive technology to teach emotion recognition to students with Asperger syndrome: a pilot study. Remedial and Special Education, 28(3), 174-181.

LaCava, P. G., Rankin, A., Mahlios, E., Cook, K., \& Simpson, R. L. (2010). A single case design evaluation of a software and tutor intervention addressing emotion recognition and social interaction in four boys with ASD. Autism, 14(3), 161-178.

Lahm, E. A. (1996). Software that engages young children with disabilities. Focus on Autism and other Developmental Disabilities, 11 (2), $115-124$.

Lanyi, C. S., \& Tilinger, A. (2004). Multimedia and virtual reality in the rehabilitation of autistic children. ICCHP, 3118, 22-28.

Massaro, D. W., \& Bosseler, A. (2006). Read my lips: the importance of the face in a computer-animated tutor for vocabulary learning by children with autism. Autism, 10(5), 495-510.

Mechling, L., \& Savidge, E. J. (2011). Using a personal digital assistant to increase completion of novel tasks and independent transitioning by students with autism spectrum disorder. Journal of Autism \& Developmental Disorders, 41, 687-704.

Mechling, L., Gast, D., \& Seid, N. (2009). Using a personal digital assistant to increase independent task completion by students with autism spectrum disorder. Journal of Autism and Developmental Disorders, 39(10), 1420-1434. 
Miller, N., \& Neuringer, A. (2000). Reinforcing variability in adolescents with autism. Journal of Applied Behaviour Analysis, 33(2), 151-165.

Mineo, B., Ziegler, W., Gill, S., \& Salkin, D. (2009). Engagement with electronic screen media among students with autism spectrum disorders. Journal of Autism and Developmental Disorders, 39(1), 172-187.

Mitchell, P., Parsons, S., \& Leonard, A. (2007). Using virtual environments for teaching social understanding to 6 adolescents with autistic spectrum disorders. Journal of Autism and Developmental Disorders, 37(3), 589-600.

Moore, M., \& Calvert, S. (2000). Brief report: vocabulary acquisition for children with autism: teacher or computer instruction. Journal of Autism and Developmental Disorders, 30, 359-362.

Moore, D., McGrath, P., \& Thorpe, J. (2000). Computer-aided learning for people with autism - a framework for research and development. Innovations in Education and Training International, 37(3), 218228.

Moore, D., Cheng, Y., McGrath, P., \& Powell, N. J. (2005). Collaborative virtual environment technology for people with autism. Focus on Autism and Other Developmental Disabilities, 20(4), 231-243.

Orsmond, G. I., \& Kuo, H.-Y. (2011). The daily lives of adolescents with an autism spectrum disorder: discretionary time use and activity partners. Autism, 15(5), 579-599.

Panyan, M. V. (1984). Computer technology for autistic students. Journal of Autism and Developmental Disorders, 14(4), 375-382.

Parsons, S., \& Mitchell, P. (2002). The potential of virtual reality in social skills training for people with autistic spectrum disorders. Journal of Intellectual Disability Research, 46(5), 430-443.

Parsons, S., Mitchell, P., \& Leonard, A. (2004). The use and understanding of virtual environments by adolescents with autistic spectrum disorders. Journal of Autism and Developmental Disorders, 34(4), 449-466.

Parsons, S., Mitchell, P., \& Leonard, A. (2005). Do adolescents with autistic spectrum disorders adhere to social conventions in virtual environments? Autism, 9(1), 95-117.

Parsons, S., Leonard, A., \& Mitchell, P. (2006). Virtual environments for social skills training: comments from two adolescents with autistic spectrum disorder. Computers \& Education, 47(2), 186-206.

Pennington, R. C. (2010). Computer-assisted instruction for teaching academic skills to students with autism spectrum disorders: a review of literature. Focus on Autism and Other Developmental Disabilities, 25(4), 239-248.

Porayska-Pomsta, K., Frauenberger, C. et al. (2011). Developing technology for autism: an interdisciplinary approach. Personal and Ubiquitous Computing

Rajendran, G. (2013). Virtual environments and autism: a developmental psychopathological approach. Journal of Computer Assisted Learning, 29(4), 334-347.

Rajendran, G., \& Mitchell, P. (2000). Computer mediated interaction in Asperger's syndrome: the Bubble Dialogue program. Computers \& Education, 35, 189-207.

Ramdoss, S., Lang, R., Mulloy, A., Franco, J., O’Reilly, M., Didden, R., et al. (2011a). Use of computer-based interventions to teach communication skills to children with autism spectrum disorders: a systematic review. Journal of Behavioural Education, 20, 55-76.

Ramdoss, S., Mulloy, A., Lang, R., O'Reilly, M., Sigafoos, J., Lancioni, G., et al. (2011b). Use of computer-based interventions to improve literacy skills in students with autism spectrum disorders: a systematic review. Research in Autism Spectrum Disorders, 5, 1306-1318.

Ramdoss, S., Machalicek, W., Rispoli, M., Mulloy, A., Lang, R., \& O'Reilly, M. (2012). Computer-based interventions to improve social and emotional skills in individuals with autism spectrum disorders: a systematic review. Developmental Neurorehabilitation, 15(2), 119-135.
Rayner, C., Denholm, C., \& Sigafoos, J. (2009). Video-based intervention for individuals with autism: key questions that remain unanswered. Research in Autism Spectrum Disorders, 3(2), 291-303.

Rehfeldt, R. A., Kinney, E. M., Root, S., \& Stromer, R. (2004). Creating activity schedules using Microsoft Powerpoint. Journal of Applied Behaviour Analysis, 37(1), 115-128.

Schwartz, C., Bente, G., Gawronski, A., Schilbach, L., \& Vogeley, K. (2010). Responses to nonverbal behaviour of dynamic virtual characters in high-functioning autism. Journal of Autism and Developmental Disorders, 40, 100-111.

Self, T., Scudder, R., Weheba, G., \& Crumrine, D. (2007). A virtual approach to teaching safety skills to children with autism spectrum disorder. Topics in Language Disorders, 27(3), 242-253.

Shane, H., \& Albert, P. (2008). Electronic screen media for persons with autism spectrum disorders: results of a survey. Journal of Autism and Developmental Disorders, 38(8), 1499-1508.

Silver, M., \& Oakes, P. (2001). Evaluation of a new computer intervention to teach people with autism or Asperger syndrome to recognise and predict emotion in others. Autism, 5(3), 299-316.

Speer, L. L., Cook, A. E., McMahon, W. N., \& Clark, E. (2007). Face processing in children with autism: effects of stimulus contents and type. Autism, 11, 265-277.

Strickland, D. (1997). Virtual reality for the treatment of autism (Virtual Reality in Neuro-Psycho-Physiology. G. Riva (Ed.)). Amsterdam: Ios Press.

Strickland, D., Marcus, L. M., Mesibov, G., \& Hogan, K. (1996). Brief report: two case studies using virtual reality as a learning tool for autistic children. Journal of Autism and Developmental Disorders, 26(6), 651-659.

Strickland, D., McAllister, D., Coles, C. D., \& Osborne, S. (2007). An evolution of virtual reality training designs for children with autism and fetal alcohol spectrum disorders. Topics in Language Disorders, 27(3), 226-241.

Stromer, R., Kimball, J. W., Kinney, E. M., \& Taylor, B. A. (2006). Activity schedules, computer technology and teaching children with autism spectrum disorders. Focus on Autism and Other Developmental Disabilities, 21(1), 14-24.

Sugasawara, H., \& Yamamoto, J. (2007). Computer-based teaching of word construction and reading in two students with developmental disabilities. Behavioural Interventions, 22, 263-277.

Swettenham, J. (1996). Can children with autism be taught to understand false belief using computers? Journal of Child Psychology and Psychiatry, 37(2), 157-165.

Tanaka, J. W., Wolf, J. M., Klaiman, C., Koenig, K., Cockburn, J., Herlihy, L., et al. (2010). Using computerized games to teach face recognition skills to children with autism spectrum disorder: the Let's Face It! program. Journal of Child Psychology and Psychiatry, 51(8), 944-952.

Tjus, T., Heimann, M., \& Nelson, K. E. (1998). Gains in literacy through the use of specially developed multimedia strategy: positive findings from 13 children with autism. Autism, 2(2), 139-156.

Tjus, T., Heimann, M., \& Nelson, K. E. (2001). Interaction patterns between children and their teachers when using a specific multi-media and communication strategy: observations from children with autism and mixed intellectual disabilities. Autism, 5(2), 175-187.

Trepagnier, C. Y., Sebrechts, M. M., Finkelmeyer, A., Stewart, W., Woodford, J., \& Coleman, M. (2006). Simulating social interaction to address deficits of autistic spectrum disorder in children. Cyberpsychology and Behavior, 9(2), 213-217.

Trepagnier, C. Y., Olsen, D. E., Boteler, L., \& Bell, C. A. (2011). Virtual conversation partner for adults with autism. Cyberpsychology, Behavior and Social Networking, 14(1-2), 21-27.

Wallace, S., Parsons, S., Westbury, A., White, K., White, K., \& Bailey, A. (2010). Sense of presence and atypical social judgements in immersive virtual environments. Autism, 14(3), 199-213. 
Whalen, C., Moss, D., Ilan, A. B., Vaupel, M., Fielding, P., MacDonald, K., et al. (2010). Efficacy of TeachTown: basics computer-assisted intervention for the Intensive Comprehensive Autism Program in Los Angeles Unified School District. Autism, 14(3), 179-197.

Wilkinson, N., Ang, R. P., \& Goh, D. H. (2008). Online video game therapy for mental health concerns: a review. International Journal of Social Psychiatry, 54(4), 370-382.

Williams, C., Wright, B., Callaghan, G., \& Coughlan, B. (2002). Do children with autism learn to read more readily by computer assisted instruction or traditional book methods? Autism, 6(1), 71-91.

Wing, L., \& Gould, J. (1979). Severe impairments of social interaction and associated abnormalities in children: epidemiology and classification. Journal of Autism and Developmental Disorders, 9, 11-29.

Wuang, Y.-P., Wang, C.-C., Huang, M.-H., \& Su, C.-Y. (2010). The effectiveness of a simulated developmental horse-riding program in children with autism. Adapted Physical Activity Quarterly, 27, 113-126.

Yamamoto, J., \& Miya, T. (1999). Acquisition and transfer of sentence construction in autistic students: analysis by computerbased teaching. Research in Developmental Disabilities, 20(5), 355-377.

Zhu, H., Sun, Y., Zeng, J., \& Sun, H. (2011). Mirror neural training induced by virtual reality in brain-computer interfaces may provide a promising approach for the autism therapy. Medical Hypotheses, $76,646-647$. 